\title{
Hydraulic run-away: a mechanism for thermally regulated surges of ice sheets
}

\author{
A. C. Fowler and Clare Johnson \\ Mathematical Institute, Oxford University, Oxford OX1 3LB, England
}

\begin{abstract}
By using a simple parameterized model of thermomechanically coupled flow in cold ice sheets, together with a physically based sliding law which includes a description of basal drainage, we show that relationships between ice flux and ice thickness can realistically be multi-valued, and hence that hydraulically induced surges can occur. We term this mechanism hydraulic run-away, as it relies on the positive feed-back between sliding velocity and basal melt production. For this feedback to operate, it is essential that water pressure increases with water storage. This is consistent with various recent ideas concerning drainage under ice sheets, be it through a system of canals, a distributed film or a subglacial aquifer. For confined flows, such as valley glaciers (e.g. Trapridge Glacier) or topographically constrained ice streams (e.g. Hudson Strait in the Laurentide ice sheet), which are underlain by sufficiently deformable sediment, we can expect thermally regulated surges to occur, while in a laterally unconfined drainage basin (such as that which flows into the Ross Ice Shelf), we might expect ice streams to develop.
\end{abstract}

\section{INTRODUCTION}

The idea of a thermally regulated mechanism of glacier surges stems from Robin (1955). The concept is very simple. If an ice sheet is frozen at the base, then the ice flux is very small and it will thicken in time due to the surface accumulation. As it does so, the insulation afforded by the ice allows the base to warm until it reaches the melting point. At this point, the ice can slide and the resultant increased ice flux, if large enough, will draw-down the ice. In principle, this can re-freeze the base, so that a cyclic oscillation ensues. Clarke and others (1977) and Yuen and Schubert (1979) extended this idea by invoking thermal run-away: the thermomechanical coupling between ice flow and temperature through the temperature-dependence of the flow law causes a multiple-valued relation between ice flux and thickness.

To understand the import of this, consider the (lumped) mass-conservation equation

$$
\dot{h}=a-Q
$$

where $\dot{h}=\mathrm{d} h / \mathrm{d} t, a$ is accumulation rate, $Q$ is proportional to ice flux and $h$ is mean ice thickness. If $Q$ is a multi-valued (e.g. S-shaped) function of $h$, such that $h^{\prime}(Q)<0$ for $Q_{\mathrm{c}}<Q<Q_{\mathrm{m}}$ then, if $Q_{\mathrm{c}}<a<Q_{\mathrm{m}}$, periodic oscillations will occur which are manifested as surges, with quiescent phases on the lower (slow) branch $Q<Q_{\text {c }}$ being punctuated by rapid surges on the upper (fast) branch $Q>Q_{\mathrm{m}}$. This mechanism has been elaborated by Fowler (1987b).

However, thermal run-away may not be realistically possible in ice sheets and glaciers. Most simply, the multi- valuedness occurs when the basal temperature is above the melting point and so is unphysical. Indeed, Fowler and Larson (1980) showed that, with realistic thermalboundary conditions, the (unique) steady state was linearly stable, in contrast to the situation for Equation (1.1), if $Q_{\mathrm{c}}<a<Q_{\mathrm{m}}$.

Nevertheless, Robin's basic concept retains its conceptual validity and, indeed, is likely to be relevant to the surges of Trapridge Glacier (Clarke and others, 1984). More recently, a similar concept has been advanced by MacAyeal (1993a) to explain hypothetical surges of the Hudson Strait ice stream which are thought to have occurred during the Last Ice Age (Andrews and Tedesco, 1992; Clark, 1994), and for which indirect evidence exists in the deep-sea sediment record (Heinrich, 1988; Bond and others, 1992; Grousset and others, 1993). In a simple model, MacAyeal (1993b) described the oscillation by postulating that, when the base of the ice is molten, it relaxes to a dynamic state corresponding to modern ice-stream dynamics, as evidenced in West Antarctica.

As a description, this is fine but it involves an assumption, namely that a temperate base is sufficient to cause fast glacier flow in the Hudson Strait ice stream; clearly, this may not be the case, as is attested by the existence of non-streaming parts of the West Antarctic ice sheet which appear to be wet-based (e.g. Ice Stream C) and the plentiful glaciers with temperate bases which do not surge (e.g. Trapridge Glacier at the present time). The purpose of this paper is therefore to examine the interplay between thermal regime and basal sliding in greater detail, with a view to substantiating MacAyeal's vision of the Hudson Strait surges. 


\section{ICE-SHEET MODEL}

In seeking a simple but realistic model for ice-sheet motion, we make use of a lumped parameter version of a boundary-layer theory developed by Fowler (1992), based on an original idea due to Nye (1959), and subsequently developed by Lliboutry (1981). This is that large ice sheets have dynamics which can be characterized by "shear layers" near the base where the shear is largest due to the high stresses and high temperatures there. In addition, relatively high velocities cause thermal gradients to be elevated in a thermal boundary layer near the base, with the shear layer lying inside this. Because of the boundary-layer nature of the flow, it is possible to produce a parameterized model which encapsulates the dynamics.

\section{Physics of the model}

We begin by describing the physical processes and their effects; the mathematical detail follows this. The horizontal motion of ice sheets is driven by the shear stresses at depth generated by the surface slope of the ice (i.e. ice flows down the "hill" generated by its surface). This flow is thermally activated by the dependence of viscosity on temperature, and this dependence is sufficiently strong that one can effectively consider that all the shear takes place where the ice is warmest, i.e. near the bed. We call the region near the bed where the shear is concentrated a shear layer and, in this layer, the horizontal velocity $u$ rises from its value $u_{\mathrm{b}}$ (the basal sliding velocity) at the bed to a far field (i.e. far from the bed) value $u_{\infty}$, which is essentially independent of depth. Also in this layer, frictional heat causes an imbalance between the basal heat flux from the bed to the ice $q_{\mathrm{b}}$, and the heat flux delivered from the shear layer to the ice above, $q_{\mathrm{T}}$. Approximate relationships betwecn these variables can be derived.

An important constituent of the model is the determination of the heat flux into the plug flow of ice above the shear layer. If $u_{\infty}$ is very small, this should be conductive (and thus $q_{\mathrm{T}} \propto h^{-1}$, where $h$ is ice thickness) but, if $u_{\infty}$ is very large, we expect a thin thermal boundary layer to exist near the base, though we can show that the shear layer lies within this thermal boundary layer (see Fig. 1). In this case, we find $q_{\mathrm{T}} \propto u_{\infty^{\frac{1}{2}}}$, and in our simple model we simply add the conductive to the convectively induced heat transfer.

We thus propose relations between $q_{\mathrm{T}}, q_{\mathrm{b}}, u_{\infty}, u_{\mathrm{b}}$ and $h$ based on the dynamics of ice, which involve the basal shear stress $\tau$ and the basal temperature $T_{\mathrm{b}}$. We have four such relations and, in order to find an expression for the horizontal ice flux $Q \approx h u_{\infty}$, we require two further relations amongst the variables. These follow from our description of the sliding process at the base. If the base is frozen, then $u_{\mathrm{b}}=0$ and $q_{\mathrm{b}}$ is the prescribed geothermal heat flux. However, if the base is temperate, then we prescribe $T_{\mathrm{b}}=T_{\mathrm{m}}$, the melting temperature, and a suitable sliding law relating $\tau$ to $u_{\mathrm{b}}$. This relation also involves the effective pressure $N$ (ice-overburden pressure minus subglacial drainage water pressure), which must be determined by a suitable drainage theory. In particular, $N$ will depend on the water supply $Q_{\mathrm{w}}$, which is itself

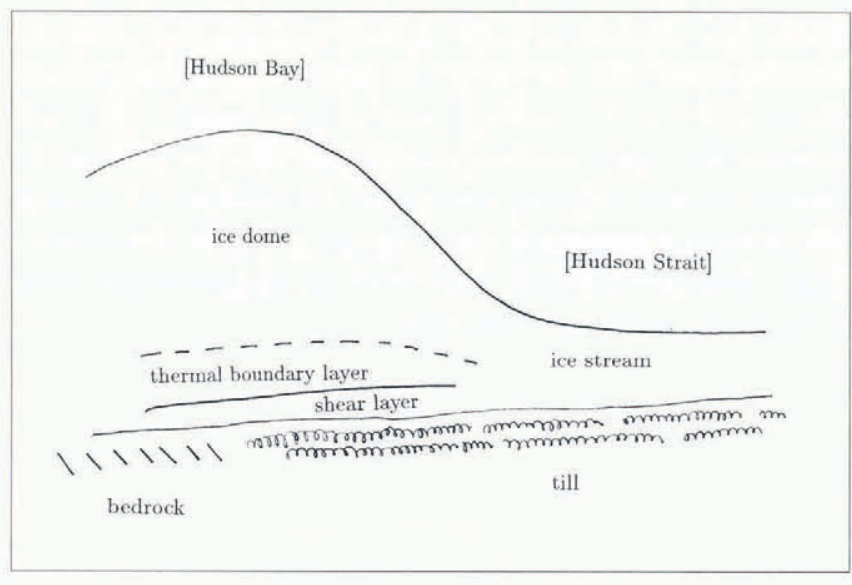

Fig. 1. Schematic representation of an ice sheel, based on conditions in the Laurentide ice sheet. The location of basal shear and thermal boundary layers is also indicated.

related to the ice flow, being proportional to the excess heat generated at the bed (geothermal plus friction minus heat lost to the cold ice above).

The sliding law is crucial to our conclusion that a multi-valued ice flux vs depth relation is possible and indeed likely. When the bed is temperate, sliding occurs but, if the velocity is low, then little frictional heat is generated and there is little water flow. Crucial to our results is the notion that the effective pressure $N$ decreases as water supply increases. This says that as water pressure increases, the hydraulic flow increases, which makes sense, but is also contrary to the drainage characteristics of Röthlisberger channels: the hypothesis $\partial N / \partial Q_{\mathrm{w}}<0$ is based on recent theories of drainage over deformable sediment beds. With this assumption, low values of $Q_{\mathrm{w}}$ correspond to high $N$, or low water pressures, and for sliding of ice over a deformable till, we expect that the basal velocity $u_{\mathrm{b}}$ increases as water pressure increases, i.e. $N$ decreases (the till becomes more mobile). Thus, low $u_{\text {b }}$ implies low $Q_{\mathrm{w}}$ implies high $N$, which is consistent with the assumption of low $u_{\mathrm{b}}$.

However, as the ice thickness increases, the conductive heat flux into the ice decreases and the water supply increases. An increase of $Q_{\mathrm{w}}$ leads to a decrease of $N$ and therefore enhances sliding. A positive feed-back exists, because the increased sliding velocity causes enhanced water production via frictional heat production, and in fact we find that the result is a run-away, in the sense that, for sufficiently large ice thickness, the "slow" mode (low $u_{\mathrm{b}}$, low $Q_{\mathrm{w}}$, high $N$ ) is not viable and a fast branch (high $u_{\mathrm{b}}$, high $Q_{\mathrm{w}}$, low $N$ ) takes over. As a consequence, we find a multiple-valued relation for ice flux $Q$ as a function of ice thickness $h$.

\section{Mathematical model}

The geometry we consider is shown in Figure 1. To fix ideas, we consider specifically a test section of the Laurentide ice sheet which extends from an ice divide down the outlet of Hudson Strait, but the concept is applicable elsewhere such as for flowlines extending south into the ice lobes which terminated the ice sheet in the Great Plains area of North America. To the south of the 
divide, the Canadian shield provides a hard base and we conceptualize the ice here as being relatively stable. North of the divide, the test section we consider lies over Hudson Bay and is channelized into the ice stream in Hudson Strait. Let the horizontal ice velocity be $u$ and the vertical coordinate be $z$ (with $z=0$ as the base). Glen's flow law may be written in the approximate form appropriate for a shearing flow

$$
\frac{\partial u}{\partial z}=A_{\mathrm{m}} \tau^{n} \exp \left[\frac{E}{R T_{\mathrm{m}}^{2}}\left(T-T_{\mathrm{m}}\right)\right]
$$

where we use the Frank-Kamenetskii (1955) approximation (for $\left|T-T_{\mathrm{m}}\right| \ll T_{\mathrm{m}}$ ) to simplify the Arrhenius term $\exp (-E / R T)$. Here, $A_{\mathrm{m}}$ is the rate factor at the pressuremelting temperature $T_{\mathrm{m}}, E$ is the activation energy, $R$ is the gas constant and $\tau$ is the basal shear stress, which can be taken as constant through the shear layer.

In the thermal boundary layer, heat advection balances conduction but, within the thinner basal shear layer, we can ignore heat advection, so that the temperature is given approximately by

$$
0=k T_{z z}+\tau u_{z}
$$

where subscripts denote partial derivatives, thus $u_{z}=\partial u / \partial z$, etc.; hence, integrating with respect to $z$,

$$
q_{\mathrm{T}}-q_{\mathrm{b}}=\tau\left(u_{\infty}-u_{\mathrm{b}}\right)
$$

where $q_{\mathrm{T}}$ is the heat flux delivered from the shear layer to the thermal boundary layer of the ice sheet, $q_{\mathrm{b}}$ is the basal heat flux at $z=0$, and $u_{\infty}$ and $u_{\mathrm{b}}$ are the far-field and basal velocities.

An integral relation between heat flux and $\tau$ is obtained by using Equation (2.1) in Equation (2.2). Multiplying Equation (2.2) by $T_{z}$ and integrating, we obtain

$$
q_{\mathrm{T}}^{2}-q_{\mathrm{b}}^{2}=\frac{2 k A_{\mathrm{m}} \tau^{n+1} R T_{\mathrm{m}}^{2}}{E} \exp \left[\frac{E}{R T_{\mathrm{m}}^{2}}\left(T_{\mathrm{b}}-T_{\mathrm{m}}\right)\right]
$$

where we have used the fact that the exponential term tends to asymptotically small values when $z$ extends beyond the shear layer (Fowler, 1992).

The basal shear stress is given by $\tau=\rho g h \sin \alpha$, where $\rho$ is density, $g$ is gravity, $h$ is ice depth and $\sin \alpha$ is the surface slope. In our parametric approach, we take $h$ as the divide height, $l$ as the length of the test section the diameter of Hudson Bay) and we take $\sin \alpha \approx h / l$, so that

$$
\tau=\rho g h^{2} / l \text {. }
$$

In reality, $u_{\infty}$ must change from zero at the divide to a large value at the outlet. In our lumped approach, it is taken to be an average value. Then the mean depth is $h / 2$, the area of the test section is $\frac{1}{2} l h$, while the icedrainage flux is $\frac{1}{2} h u_{\infty}$. It follows that mass conservation can be expressed as $\mathrm{d}\left[\frac{1}{2} l h\right] / \mathrm{d} t=l a-\frac{1}{2} h u_{\infty}$, whence

$$
\dot{h}=2 a-\left(h u_{\infty} / l\right)
$$

where $a$ is the average accumulation rate over Hudson
Bay. In general, it may depend on the atmospheric adiabatic lapse rate, in which case $a$ would be a function of the mean ice depth $h / 2$.

In the thermal boundary layer, shear heating is negligible (it is concentrated in the warmer shear layer), so that since the boundary-layer temperature relaxes quickly to a steady state)

$$
\rho c_{\mathrm{p}}\left(u T_{x}+w T_{z}\right) \approx k T_{z z}
$$

where $x$ is the horizontal coordinate (see Fowler (1992) for further details). The temperature profile necessarily evolves with $x$ and it is indeed possible (with $u=u_{\infty}$, $w=0, T_{\mathrm{b}}=$ constant, for example) to find a similarity solution for $T$ (indeed, this can even be done if $u_{\infty}=$ $\left.u_{\infty}(x)\right)$. With $T=T_{\mathrm{b}}$ on $z=0$ and $T=T_{\infty}$ as $z \rightarrow \infty$ (i.e. outside the boundary layer), the similarity solution is

$$
T=T_{\infty}+\left(T_{\mathrm{b}}-T_{\infty}\right) f\left[\left(\frac{\rho c_{\mathrm{p}} u_{\infty}}{k x}\right)^{\frac{1}{2} z} \frac{2}{2}\right]
$$

(and $f(\xi)=\operatorname{erfc}(\xi)$ ), whence the average heat flux delivered to the thermal boundary layer from the shear layer $)$ is $-f^{\prime}(0) \times\left[\rho c_{\mathrm{p}} u_{\infty} k / l\right]^{\frac{1}{2}}\left(T_{\mathrm{b}}-T_{\infty}\right)$. Since $-f^{\prime}(0)=$ $2 / \sqrt{\pi}$, we thus have

$$
q_{\mathrm{T}}=(2 / \sqrt{\pi})\left[\rho c_{\mathrm{p}} u_{\infty} k / l\right]^{\frac{1}{2}}\left(T_{\mathrm{b}}-T_{\infty}\right)+(k / h)\left(T_{\mathrm{b}}-T_{\mathrm{a}}\right)
$$

where we simply add the second term to include the heat flux due to conduction when $h$ or $u_{\infty}$ is small $\left(T_{\mathrm{a}}\right.$ is the surface temperature). Notice that a simpler approach to obtain $q_{\mathrm{T}}$ would be to take a linear temperature profile through the thermal boundary layer thickness $\delta_{\mathrm{T}}$, thus the first term would be $q_{\mathrm{T}}=k\left(T_{\mathrm{b}}-T_{\infty}\right) \delta_{\mathrm{T}}$, where from Equation (2.7), we would dimensionally estimate $\delta_{\mathrm{T}} \approx$ $\left(k l / \rho c_{\mathrm{p}} u_{\infty}\right)^{\frac{1}{2}}$. This gives the same result without the premultiplicative factor and is probably just as good.

The Equations (2.3), (2.4), (2.5), (2.6) and (2.8) provide five equations for the unknowns $u_{\infty}, q_{\mathrm{b}}, \tau, h$ and $q_{\mathrm{T}}$. However, the variables $u_{\mathrm{b}}, T_{\mathrm{b}}$ and $T_{\infty}$ remain to be prescribed. The temperature $T_{\infty}$ at the edge of the thermal boundary layer is derived from the divide temperature at an earlier time. Since heat conduction may be small (as measured by the smallness of $\delta_{\mathrm{T}}$ compared to the ice depth), the surface temperature is simply advected downwards. However, we will assume for simplicity that the surface (divide) temperature is constant, and thus we prescribe

$$
T_{\infty}=T_{\mathrm{a}} .
$$

\section{Basal conditions}

Finally, we constitute the basal values of $T$ and $u$. There are four possible states of the basal system which we will consider.

\section{(i) Frozen base \\ We prescribe}

$$
u_{\mathrm{b}}=0, q_{\mathrm{b}}=G, \text { while } T_{\mathrm{b}}<T_{\mathrm{m}}
$$

where $G$ is the prescribed geothermal heat flux. 


\section{(ii) Sub-lemperate base}

When the base reaches the pressure-melting point, sliding is initiated, but at first there is no net water production (we ignore any possible flux from the surface). In this case, we have

$$
T_{\mathrm{b}}=T_{\mathrm{m}}, q_{\mathrm{b}}=G+\tau u_{\mathrm{b}}, \text { while } 0<u_{\mathrm{b}}<u_{\mathrm{b}}{ }^{*}
$$

where $u_{\mathrm{b}}{ }^{*}$ is the "fully developed" sliding velocity detailed next.

\section{(iii) Temperate base}

When $0<q_{\mathrm{b}}<G+\tau u_{\mathrm{b}}$, then "fully developed" sliding occurs. This is the sliding commonly prescribed using a "sliding law" of the form $\tau=f\left(u_{\mathrm{b}}, N\right)$, where $N$ is the effective basal water pressure $\left(=p_{\mathrm{i}}-p_{\mathrm{w}}\right.$, where $p_{\mathrm{i}}$ is iceoverburden pressure and $p_{\mathrm{w}}$ is basal water pressure). Sliding theories for hard beds developed in the 1960s and 1970 s led to that enunciated by Lliboutry (1979). In its simplest expression, this gives $\tau / N=f\left(u_{\mathrm{b}} / N^{n}\right)$ (Lliboutry, 1987), where $n$ is the exponent in Glen's law. When $f$ is a power law, we have the relation

$$
\tau=c u_{\mathrm{b}}^{r} N^{s},
$$

(consistent with Lliboutry's result if $n r+s=1$ ), derived theoretically by Fowler (1987a), with typical values $r \approx$ $1 / 4, s \approx 1 / 4$. Laboratory experimental results of Budd and others (1979) are also consistent with Equation (2.12), with (at high $N$ ) $r=s=1 / 3, c \approx 0.18 \mathrm{~m}^{-\frac{1}{3}}$ bar $^{\frac{2}{3}}$ year $^{\frac{1}{3}}\left(1\right.$ bar $=10^{5} \mathrm{~Pa}, 1$ year $\left.=3 \times 10^{7} \mathrm{~s}\right)$; at low $N$, more appropriate values were $r=s=1$. Bindschadler (1983) also found some consistency with Equation (2.12) using measurements on Variegated Glacier and indeed found a similar value of $c$.

However, these results apply for ice sliding over a lumpy bed, where the principal resistance is due to the flow past the bumps. For the situation of relevance here, where the principal resistance is due to deformation of a layer of saturated subglacial sediment, a simple sliding law is just

$$
\tau_{\mathrm{b}}=\eta u_{\mathrm{b}} / h_{\mathrm{T}}
$$

where $\eta$ is the viscosity of the till and $h_{\mathrm{T}}$ is its depth. The effective water-pressure dependence arises through influence on the till viscosity. A law proposed by Boulton and Hindmarsh (1987) based on seven measurements at Breidamerkurjökull is $\dot{\varepsilon}=A \tau^{a} N^{-b}$, in which case we could write Equation (2.13) in the form of Equation (2.12), with $r=1 / a \approx 0.75, s=b / a \approx 1.4$ and $c=$ $\left(A h_{\mathrm{T}}\right)^{-r}$. Boulton's law is controversial, however, and values of $\tau$ and $N$ appropriate to Ice Stream B $\tau=$ 0.15 bar, $N=0.5$ bar) give a velocity of $9 \mathrm{~m}$ year $^{-1}$ for till of thickness $8 \mathrm{~m}$, as opposed to the $500 \mathrm{~m}$ year $^{-1}$ observed. Alley and others (1987) estimated the viscosity of till under Ice Stream B as $10^{10} \mathrm{Pas}$.

Despite concerns with the Boulton-Hindmarsh rheology, it is the simplest type of rheology which mimics the effect which increasing water pressure has, namely to decrease till viscosity. However, it suffers one important conceptual limitation. Since the actual deformation of till involves particles moving round and past each other, dilation is necessary to accommodate the flow. Therefore, it is only realistic to suppose that the viscosity $\eta=$ $N^{b} / A \tau^{a-1}$ tends to zero as $N \rightarrow 0$ for an unconfined flow (when it dilates to a slurry). For flow in a confined channel (such as a till layer), deformation causes dilation and consequently normal stresses, so that it is properly a non-Newtonian material. The simplest way in which a non-zero viscosity at $N=0$ can be included is to replace $N$ in Equation $(2.12)$ by $N+N_{0}$, so that

$$
\tau=c u_{\mathrm{b}}^{r}\left(N_{0}+N\right)^{s} .
$$

There is little to constrain such an $N_{0}$ but a least-squares fit to Boulton and Hindmarsh's limited data yields $N_{0}=$ 0.045 bar, comparable to the yield stress, and suggests that normally a relationship such as Equation (2.12) may suffice, although there is very little to constrain the choice of $c, r$ and $s$.

The effective pressure $N$ depends on the volume flux $Q$ of water through the drainage system. Here we are concerned with the drainage from a till-based system, for which Walder and Fowler (1994) suggested that a system of "canals" scoured from the till will exist, within which $N$ is essentially a (decreasing) function of $Q$; since $Q$ increases downstream, $N$ will decrease and so also will the viscosity, as is inferred for Ice Stream B (Alley and others, 1987). Taking into account basal topography, we then expect a reticular network of interwoven canals with spacing controlled by the wavelength of topographic variability.

The existence of a basal system of canals is by no means certain. A modified viewpoint is that the water simply ponds and drains as a patchy but connected water film (Alley, 1989). A sliding law based on the corresponding hydraulic system has been proposed and used by Alley (1990); he also found multiple dynamic states and indeed the crucial point is that the basal velocity increases with the water supply. Thus, while the precise quantitative nature of the basal hydrology is of importance, from the point of view of the sliding law, it is only a detail.

The excess heat production at the bed is $G+\tau u_{\mathrm{b}}-q_{\mathrm{b}}$ and this produces a downward melt velocity of $G+\tau u_{\mathrm{b}}$ $\left.-q_{\mathrm{b}}\right) / \rho_{\mathrm{w}} L$, where $L$ is latent heat and $\rho_{\mathrm{w}}$ is the density of water. If the spacing of an assumed reticular drainage network is $w_{\mathrm{d}}$, then the flux of water per channel is given (in parameterized form) by

$$
Q_{\mathrm{w}}=\frac{\left(G+\tau u_{\mathrm{b}}-q_{\mathrm{b}}\right) l w_{\mathrm{d}}}{\rho_{\mathrm{w}} L}
$$

and $N$ is given by a relation such as that of Walder and Fowler (1994). For canals incised into relatively finegrained sediments, they put (with $\sin \alpha \approx h / l$ )

$$
N=\frac{c^{\prime} D_{\mathrm{s}} h^{\frac{1}{6}}}{l^{\frac{1}{6}} Q_{\mathrm{w}^{\frac{1}{3}}}^{\frac{1}{3}}}
$$

where $D_{\mathrm{s}}$ is a "characteristic" size of suspended grains in the water flow and $c^{\prime} \approx 1.1 \times 10^{4}$ bar $^{-\frac{1}{3}}$. A representative value of $D_{\mathrm{s}}$ might be $D_{\mathrm{s}}=0.1 \mathrm{~mm}=10^{4} \mathrm{~m}$, in which case a slope of $10^{-3}$ and a water flux of $1 \mathrm{~m}^{3} \mathrm{~s}^{-1}$ gives $N \approx 0.3$ bar. It must be emphasized that Equation 
(2.16) is possibly a crude representation and the relationship itself describes only one possible drainage scenario; others are arguably just as plausible.

In using Equation (2.12) or Equation (2.14), together with Equations (2.15) and (2.16), to prescribe $\tau$ in terms of $u_{\mathrm{b}}$, we have to consider what happens as $Q_{\mathrm{w}} \rightarrow 0$. Equation (2.16) cannot strictly apply for small $Q_{\mathrm{w}}$, since it implies that $N \rightarrow \infty$ as $Q_{\mathrm{w}} \rightarrow 0$. In fact, for very small values of $Q_{\mathrm{w}}, N$ will increase rapidly from zero (flotation) at the onset of channelized flow to a value $N \approx \tilde{p}$, where $\tilde{p}$ is a critical effective pressure relating creep properties of till to those of ice (Walder and Fowler, 1994). Based on the Boulton-Hindmarsh rheology, $\tilde{p} \approx 8 \mathrm{bar}$, while for less viscous till, $\tilde{p}$ could be higher. At any rate, this suggests that the correct limiting value of $N$ to use as $Q_{\mathrm{w}} \rightarrow 0$ is $\tilde{p}$. A practical way to model this is to define $\tilde{Q}_{\mathrm{w}}$ via

$$
\tilde{p}=\frac{c^{\prime} D_{\mathrm{s}} h^{\frac{1}{6}}}{l^{\frac{1}{6}} \tilde{Q}_{\mathrm{w}}^{\frac{1}{3}}}
$$

and then replace $Q_{\mathrm{w}}$ in Equation $(2.16)$ by $\left(Q_{\mathrm{w}}+\tilde{Q}_{\mathrm{w}}\right)$. Since we expect $\tilde{Q}_{w}$ to be "small", there is little difference made in doing this. We then use Equation (2.12) and the fully developed sliding velocity $u_{\mathrm{b}}{ }^{*}$ is defined by

$$
\tau=c u_{\mathrm{b}}^{* r} \tilde{p}^{s} .
$$

Now in fact, since $\tilde{Q}_{\mathrm{w}}$ is "small" and $\tilde{p}$ is "large", we have that $u_{\mathrm{b}}{ }^{*}$ is also small, and in practice we can ignore the sub-temperate region ((ii) above) altogether. We thus take the sliding law in the form

$$
\begin{aligned}
\tau & =c u_{\mathrm{b}}{ }^{r} N^{s}, \\
N & =\frac{c^{\prime} D_{\mathrm{s}} h^{\frac{1}{6}}}{l^{\frac{1}{6}} Q_{\mathrm{w}}^{\frac{1}{3}}}, \\
Q_{\mathrm{w}} & =\frac{\left(G+\tau u_{\mathrm{b}}-q_{\mathrm{b}}\right) l w_{\mathrm{d}}}{\rho_{\mathrm{w}} L}
\end{aligned}
$$

while $Q_{\mathrm{w}}>0$, and note that as $Q_{\mathrm{w}} \rightarrow 0$, then (formally) $N \rightarrow \infty$ and $u_{\mathrm{b}} \rightarrow 0$. The second of these allows for a continuous join to the frozen regime where $u_{\mathrm{b}}=0$.

\section{Molten base}

A further regime is possible, which we simply ignore. If the heat flux to the ice reaches zero, i.e. if $q_{\mathrm{b}}=0$, then a basal layer of temperate ice forms (e.g. Hutter and others, 1988), and in this case the whole ice-dynamics model must change, since the ice viscosity depends on moisture content (Lliboutry, 1976). In such a situation, moisture is produced within the ice and drainage of this water to the basal system can only enhance the instability we envisage. However, it is not specifically included in our model and is in fact unlikely to occur with the present assumptions.

\section{ANALYSIS}

The Equations (2.3), (2.4), (2.5), (2.6), (2.8) and (2.9), together with the boundary conditions (2.10) or (2.14),
(2.15) and (2.16), are scaled by choosing

$$
\begin{aligned}
u_{\mathrm{b}}, u_{\infty} & \sim[u], \tau \sim[\tau], h \sim[h], t \sim[t], \\
T_{\mathrm{b}}-T_{\mathrm{m}} & \sim T_{\infty}-T_{\mathrm{m}} \sim T_{\mathrm{a}}-T_{\mathrm{m}} \sim \Delta T, \\
Q_{\mathrm{w}} & \sim\left[Q_{\mathrm{w}}\right], N \sim[N], a \sim[a], q_{\mathrm{T}}, q_{\mathrm{b}} \sim G ;
\end{aligned}
$$

(that is to say, we define dimensionless variables $u^{*}, \tau^{*}$, etc. by writing $u=[u] u^{*}, \tau=[\tau] \tau^{*}$; in the sequel, we drop the asterisks for convenience). We choose balances via

$$
\begin{array}{rlrl}
G & =[\tau][u], & & \\
{\left[Q_{\mathrm{w}}\right]} & =\frac{G l w_{\mathrm{d}}}{\rho_{\mathrm{w}} L}, & {[N]=\frac{c^{\prime} D_{\mathrm{s}}[h]^{\frac{1}{6}}}{l^{\frac{1}{6}}\left[Q_{\mathrm{w}}\right]^{\frac{1}{3}}},} \\
\frac{[h]}{[t]} & =2[a]=\frac{[h][u]}{l}, & {[\tau]=\rho g[h]^{2} / l .}
\end{array}
$$

From these we derive

$$
\begin{aligned}
& {[h]=\frac{G}{2 \rho g[a]}, \quad[u]=2 l[a] /[h],} \\
& {[\tau]=G /[u],}
\end{aligned}
$$

and for values

$$
\begin{aligned}
& G \sim 0.05 \mathrm{~W} \mathrm{~m}^{-2}, \rho \sim 10^{3} \mathrm{~kg} \mathrm{~m}^{-3}, g \sim 10 \mathrm{~m} \mathrm{~s}^{-2}, \\
& \quad[a] \sim 10 \mathrm{cmyear}^{-1}, l \sim 2000 \mathrm{~km},
\end{aligned}
$$

we find

$$
\begin{aligned}
& {[h] \sim 750 \mathrm{~m},[u] \sim 500 \text { m year }^{1},[\tau] \sim 0.03 \text { bar }, } \\
& {[t] \sim 3750 \text { year. } }
\end{aligned}
$$

These values are approximately representative of fastflowing ice streams and are perhaps relevant to the conditions of a temperate bed. The corresponding dimensionless model equations are

$$
\begin{aligned}
q_{\mathrm{T}}^{2} & =q_{\mathrm{b}}^{2}+2 \mu_{1} h^{8} \mathrm{e}^{\lambda T_{\mathrm{b}}}, \\
q_{\mathrm{T}} & =q_{\mathrm{b}}+h^{2}\left(u_{\infty}-u_{\mathrm{b}}\right), \\
\tau & =h^{2}, \\
\dot{h} & =a-h u_{\infty}, \\
q_{\mathrm{T}} & =\mu_{2} u_{\infty}^{\frac{1}{2}}\left(T_{\mathrm{b}}-T_{\mathrm{a}}\right)+(\delta / h)\left(T_{\mathrm{b}}-T_{\mathrm{a}}\right),
\end{aligned}
$$

together with

$$
q_{\mathrm{b}}=1, u_{\mathrm{b}}=0, \quad \text { if } \quad T_{\mathrm{b}}<0,
$$

or

$$
\begin{aligned}
T_{\mathrm{b}} & =0, \quad \tau=\mu_{3} u_{\mathrm{b}}^{r} N^{s}, \\
Q_{\mathrm{w}} & =1+h^{2} u_{\mathrm{b}}-q_{\mathrm{b}}, \\
N & =h^{\frac{1}{6}} / Q_{\mathrm{w}}^{\frac{1}{3}}, \quad \text { if } \quad Q_{\mathrm{w}}>0 .
\end{aligned}
$$

The parameters are defined by

$$
\begin{gathered}
\lambda=\frac{E \Delta T}{R T_{\mathrm{m}}^{2}}, \quad \mu_{1}=\frac{k A_{\mathrm{m}}[\tau]^{n+1} R T_{\mathrm{m}}^{2}}{G^{2} E} \\
\mu_{2}=\frac{2}{\sqrt{\pi}}\left[\frac{\rho c_{\mathrm{p}} k[u]}{l}\right]^{\frac{1}{2}} \frac{\Delta T}{G}, \\
\delta=\frac{k \Delta T}{G[h]}, \quad \mu_{3}=\frac{c[u]^{r}[N]^{s}}{[\tau]}
\end{gathered}
$$


and we use values

$$
\begin{aligned}
k & =2.1 \mathrm{~W} \mathrm{~m}^{-1} \mathrm{~K}^{-1}, \quad \mathrm{R}=8.3 \mathrm{~J} \mathrm{~mol}^{-1} \mathrm{~K}^{-1}, T_{\mathrm{m}}=273 \mathrm{~K}, \\
A_{\mathrm{m}} & =5.3 \times 10^{-15} \mathrm{kPa}^{-3} \mathrm{~s}^{-1}, n=3, \\
E & =139 \mathrm{~kJ} \mathrm{~mol}^{-1}, \rho=917 \mathrm{~kg} \mathrm{~m}^{-3}, g=9.8 \mathrm{~m} \mathrm{~s}^{-2}, \\
l & =2000 \mathrm{~km},[a]=0.1 \mathrm{~m}_{\mathrm{year}}^{-1}, c_{\mathrm{p}}=2009 \mathrm{~J} \mathrm{~kg}^{-1} \mathrm{~K}^{-1}, \\
G & =0.05 \mathrm{~W} \mathrm{~m}^{-2}, \Delta T=30 \mathrm{~K} .
\end{aligned}
$$

We then have

$$
\begin{aligned}
\lambda \sim 6.7, \quad & \mu_{1} \sim 1.5 \times 10^{-6}, \\
\mu_{2} & \sim 3.7, \quad \delta \sim 1.7
\end{aligned}
$$

and $\mu_{3}$ is rather uncertain. Comparison of observed stresses $\sim 0.15$ bar and velocities $500 \mathrm{~m}$ year $^{-1}$ at Ice Stream B would suggest $\mu_{3} \sim 5$, for example.

\section{Cold approximation}

We use the fact that $\mu_{1} \ll 1$ to approximate the relations in Equations (3.6) and (3.7). We have that $q_{\mathrm{T}} \approx q_{\mathrm{b}}=1$, and then

$$
u_{\infty} \approx \mu_{1} h^{6} \mathrm{e}^{-\lambda\left|T_{\mathrm{b}}\right|}, 1 \approx \frac{\delta\left(1-\left|T_{\mathrm{b}}\right|\right)}{h}
$$

where we take $T_{\mathrm{a}}=-1$ as constant (more generally it might be a function of $h)$. Thus $\left|T_{\mathrm{b}}\right|=1-(h / \delta)$ and the ice flux is

$$
Q \approx \mu_{1} h^{7} \exp [-\lambda\{1-(h / \delta)\}]
$$

It increases monotonically with $h$ until $T_{\mathrm{b}}=0$, which is at $h \approx \delta$, and where $Q \approx \mu_{1} \delta^{7} \sim 0.66 \times 10^{4}$. Thus, the ice is virtually stagnant if the base is frozen.

\section{Temperate approximation}

When $T_{\mathrm{b}}$ reaches zero at the base, we adopt the temperate conditions (3.8), which gives (with $\left|T_{\mathrm{a}}\right|=1$ )

$$
\begin{aligned}
q_{\mathrm{T}}^{2} & =q_{\mathrm{b}}{ }^{2}+2 \mu_{1} h^{8}, \\
q_{\mathrm{T}} & =q_{\mathrm{b}}+h^{2}\left(u_{\infty}-u_{\mathrm{b}}\right), \\
q_{\mathrm{T}} & =\mu_{2} u_{\infty}{ }^{\frac{1}{2}}+(\delta / h), \\
{\left[1+h^{2} u_{\mathrm{b}}-q_{\mathrm{b}}\right]^{s / 3} } & =\frac{\mu_{3} u_{\mathrm{b}}{ }^{r}}{h^{2-(s / 6)}} .
\end{aligned}
$$

These imply, successively, $q_{\mathrm{T}} \approx q_{\mathrm{b}}=q$, say, $u_{\infty} \approx u_{\mathrm{b}}=u$, say, and thus we have to solve

$$
\begin{gathered}
\dot{h}=a-h u, \\
{\left[1+h^{2} u-\mu_{2} u^{\frac{1}{2}}-(\delta / h)\right]^{s / 3}=\frac{\mu_{3} u^{r}}{h^{2-(s / 6)}} .}
\end{gathered}
$$

These equations are valid providing $0<q_{\mathrm{b}}<1+h^{2} u_{\mathrm{b}}$ (the dimensionless version of $0<q_{\mathrm{b}}<G+\tau u_{\mathrm{b}}$, corresponding to a temperate base). From Equations (3.14), $q_{\mathrm{T}}-q_{\mathrm{b}} \approx \mu_{1} h^{8} / q$ and $u_{\mathrm{b}} \approx u_{\infty}-\mu_{1} h^{6} / q$. The coldtemperate transition is when $u_{\mathrm{b}}=0$, so the temperate conditions are valid if $u_{\mathrm{b}} \geq 0$, i.e. $u>\mu_{1} h^{6} / q$; equivalently (since also $q \approx 1$ when $\left.u_{\mathrm{b}}=0\right) u>\mu_{1} h^{6}$ and, since the transition occurs when $h \approx \delta$, this is $u>\mu_{1} \delta^{6}$.
The temperate-molten transition is when $q=0$. However, the third of Equations (3.14) implies that $q>0$, so that in this model, basal molten zones do not occur.

We now consider Equation (3.15). Denote the leftand righthand sides as $P(h, u), R(h, u)$ and also put $p=1$ $+h^{2} u-\mu_{2} u^{\frac{1}{2}}-\delta / h$, thus $P=p^{s / 3}$. For given $u>0, p$ and hence $P$ is monotone increasing with positive $h$, while $R$ is monotone decreasing (we assume $s<12$ ). Therefore, there is a unique positive $h$ for each value of $u$.

Alternatively, fix a value of $h>0$. The function $p$ is a quadratic in $u^{\frac{1}{2}}$ with no roots if $h>h_{\mathrm{c}}=\left[\left(\delta^{2}+\mu_{2}^{2}\right)^{\frac{1}{2}}\right.$ $+\delta] / 2$, two positive roots if $\delta<h<h_{\mathrm{c}}$ and one positive root if $h<\delta$. On the other hand, $R$ increases with $u$ and, since $p^{\frac{1}{2}}=R^{3 / 2 s} \propto\left(u^{\frac{1}{2}}\right)^{3 r / s}$, then if $r>s / 3$ (as we assume) $R>P$ for large enough $u^{\frac{1}{2}}$ (since $p^{\frac{1}{2}} \sim u^{\frac{1}{2}}$ as $u^{\frac{1}{2}} \rightarrow \infty$ ). By considering intersections of $P$ and $R$, we then see that for large $\mu_{3}$ there will be a unique value of $u$ (given $h$ ) for $h>\delta$, while for small $\mu_{3}, u(h)$ will be multi-valued. The two different possibilities are illustrated in Figure 2, using values given in Equation (3.11) for $\mu_{3}=1.0$ and $\mu_{3}=$ 20.0. For the values in Equation (3.11) we find that a multi-valued flux/depth relation occurs if $\mu_{3}<\mu^{*}$ $\approx 16.98$. The lefthand nose of the curve, at $h=h_{\mathrm{m}}$, is to the left of the cold-temperate transition (i.e. $h \approx \delta$ ) if $\mu_{3}<\tilde{\mu} \approx 2.01$.

An analytic approximation to the relation can be obtained when $\mu_{3}$ is small. In that case, we can approximate the solution of Equations (3.15) as follows.

ice flux $Q$

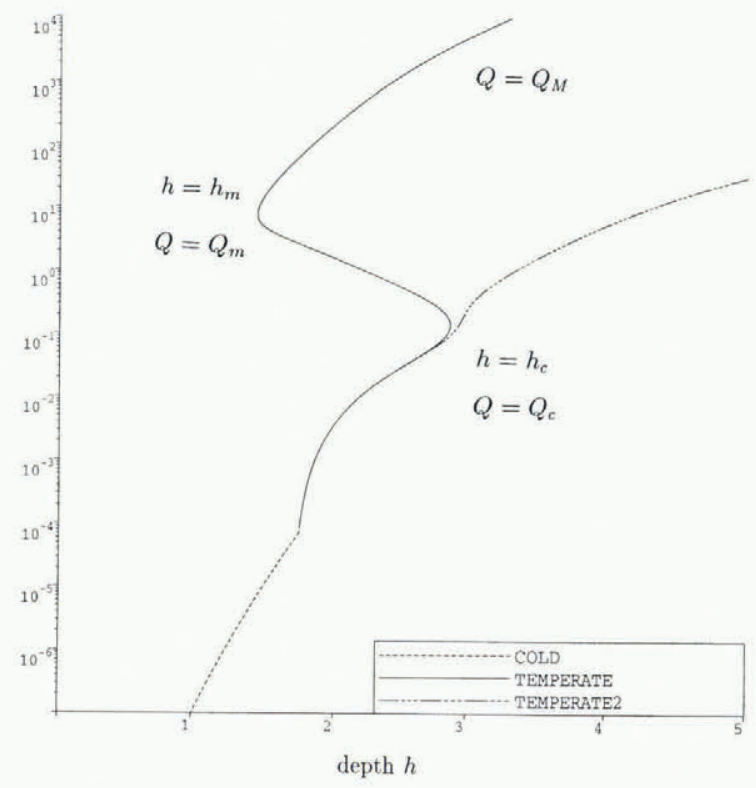

Fig. 2. Two flux curves for the parameters in Equation (3.11), together with $\mu_{3}=1$ (multi-valued) and $\mu_{3}=20$ (single-valued). With $\mu_{3}=1$, the slow nose is at $h=h_{\mathrm{c}}=2.86$, and the fast nose is at $h=h_{\mathrm{m}}=1.44$. These correspond to depths of 2145 and $1080 \mathrm{~m}$, respectively. At $h_{\mathrm{c}}$, the velocity is $0.034(\sim 17 \mathrm{~m}$ year $\left.{ }^{-1}\right)$, while at the same value on the fast branch it is $1.18 \times 10^{3}\left(\sim 590\right.$ kmyear $^{-1}$ or $\left.2 \mathrm{~cm} \mathrm{~s}^{-1}\right)$. At $h_{\mathrm{m}}$, the velocity is $5.24\left(\sim 2.6 \mathrm{~km}\right.$ year $\left.^{-1}\right)$. One can show that the consequent surge duration is approximately 0.03 , corresponding to 116 years (based on Equation (3.5)). 
The fast branch is

$$
u \sim C h^{\alpha}
$$

where

$$
C=\mu_{3}^{-3 /(3 r-s)}, \quad \alpha=\frac{3(4+s)}{2(3 r-s)},
$$

for example, if $r=s=1 / 3$, then $C \approx \mu_{3}{ }^{-9 / 2}, \alpha \approx 10$, so we expect Equations (3.17) to be accurate even for moderately low $\mu_{3}$. The lower and middle branches are given by

$$
u^{\frac{1}{2}}=\frac{1}{2 h^{2}}\left[\mu_{2} \pm\left\{\mu_{2}^{2}+\delta^{2}-(2 h-\delta)^{2}\right\}^{\frac{1}{2}}\right],
$$

so the nose is at $h=h_{\mathrm{c}}$ as defined before. At the upper (i.e. larger $Q$ ) nose, $h=h_{\mathrm{m}}, u \gg 1$ and Equation (3.15) is approximated by

$$
h^{2} u-\mu_{2} u^{\frac{1}{2}}=\frac{\mu_{3}^{3 / s} u^{3 r / s}}{h^{\frac{3}{s}}\left(2-\frac{s}{6}\right)},
$$

and it follows from this that at the nose

$$
h=h_{\mathrm{c}} \sim \mu_{3}^{\nu}, u \sim \mu_{3}{ }^{-4 \nu}
$$

where

$$
\nu=(12-5 s+24 r) / 2 s .
$$

If $r=s=1 / 3$, then $\nu \approx 27$, so that again we expect $h_{\mathrm{c}}<\delta$ for moderately low $\mu_{3}$. In particular, the magnitude of the surging velocity depends sensitively on $\mu_{3}$.

We see that the sliding law can give rise to a phenomenon which we may term hydraulic run-away. If $h$ reaches $h_{\mathrm{c}}$, then there is an unstable transition to a fast-sliding mode by the enhanced production of meltwater, although the ice above remains cold. We thus have a mechanism for relaxation oscillations of the ice sheet.

\section{DISGUSSION}

The parameterized model presented here is of course crude but nevertheless it encapsulates the basic physics of sliding over deformable sediments and shows that thermally regulated surging is a feasible phenomenon. Hydraulic run-away relies on two features. First, sliding is enhanced by increased water production. Thus, the increase in frictional heating with velocity is a positive feed-back. Countering this is the negative feed-back due to the increase in heat flux from the base with increased velocity. At low $u_{\mathrm{b}}$, the second of these dominates, since $q_{\mathrm{b}} \sim u_{\mathrm{b}}^{\frac{1}{2}}$, but at higher values of $u_{\mathrm{b}}$ frictional heating predominates and a fast-sliding mode becomes possible.

As applications, we consider the Hudson Strait megasurges to be a prime example (MacAyeal, 1993a, b). We should also like to consider whether thermally regulated surging of Trapridge Glacier can be looked at from the same point of view. In this case, the base is temperate and basal water is evacuated subglacially as ground-water flow. Currently, the glacier would reside on the slow branch. A difference in the valley-glacier case is that basal meltwater is likely to be mainly surface-derived and whether the positive feed-back of ice velocity on water pressure can operate is unclear.

Lastly, we consider sheet flow over a deformable bed, i.e. where the width of the flow is much greater than the depth and where the flow is fed from a stable catchment: we have in mind the Siple Coast of Antarctica. Suppose upstream that $Q(h)$ is a monotone function (e.g. due to lack of a basal till cover) but that downstream we have $Q=Q(h)$ as in Figure 2. With conditions of continuity of $Q$ and $h$ at the join, we conjecture that, if this $Q$ value lies on the unstable part of the downstream $Q(h)$ curve, a uniform flow is laterally unstable and will break up into fast- and slow-moving parts, and that these are precisely ice streams. A study of this postulated instability is deferred to future work.

\section{ACKNOWLEDGEMENTS}

We are grateful to R. Alley and D. MacAyeal, in particular, for sharing their insights with us. C. Johnson acknowledges the award of a U.K. NERC CASE studentship (with the British Antarctic Survey).

\section{REFERENGES}

Alley, R.B. 1989. Water-pressure coupling of sliding and bed deformation: I. Water system. J. Glaciol., 35(119), 108-118.

Alley, R. B. 1990, Multiple steady states in ice-water-till systems. Ann. Glaciol., 14, 1-5.

Alley, R. B., D. D. Blankenship, C. R. Bentley and S. T. Rooney. 1987. Till beneath Ice Stream B. 4. A coupled ice-till flow model. f. Geophys. Res., 92 (B9), 8931-8940.

Andrews, J. T. and K. Tedesco. 1992. Detrital carbonate-rich sediments, northwestern Labrador Sea: implications for ice-sheet dynamics and iceberg rafting (Heinrich) events in the North Atlantic. Geology, 20 (12), 1087-1090.

Bindschadler, R. 1983. The importance of pressurized subglacial water in separation and sliding at the glacier bed. F. Glaciol., 29 (101), 3-19.

Bond, G, and 13 others. 1992. Evidence for massive discharges of icebergs into the North Atlantic Ocean during the last glacial period. Nature, $360(6401), 245-249$.

Boulton, G.S. and R. C.A. Hindmarsh. 1987. Sediment deformation beneath glaciers: rheology and geological consequences. 7. Geophys. Res., 92(B9), 90599082.

Budd, W.F., P. L. Keage and N. A. Blundy. 1979. Empirical studies of ice sliding. 7. Glaciol., 23 (89), 157-170.

Clark, P. U. 1994. Unstable behavior of the Laurentide ice sheet over deforming sediment and its implications for climate change. Quat. Res., 41(1), 19-25.

Clarke, G. K. C., U. Nitsan and W. S. B. Paterson. 1977. Strain heating and creep instability in glaciers and ice sheets. Rev. Geophys. Space Phys., 15 2), 235247.

Clarke, G. K. C., S. G. Collins and D. E. Thompson. 1984. Flow, thermal structure, and subglacial conditions of a surge-type glacier. Can. J. Earth Sci., 21 (2), 232-240.

Fowler, A. C. 1987a. Sliding with cavity formation. J. Glaciol., 33(115), $255-267$.

Fowler, A. C. 1987b. A theory of glacier surges. J. Geophys. Res., 92(B9), 9111-9120.

Fowler, A.C. 1992. Modelling ice sheet dynamics. Geophys. Astrophys. Fluid. Dyn., $63(1-4), 29-66$.

Fowler, A. C. and D. A. Larson. 1980. Thermal stability properties of a model of glacier flow. Geophys. 7. R. Astron. Soc., 63, 347-359.

Frank-Kamenetskii, D.A. 1955. Diffusion and heat exchange in chemical kinetics. Princeton, NJ, Princeton University Press. 


\section{Fowler and Johnson: Thermally regulated surges of ice sheets}

Grousset, F.E. and 7 others. 1993. Patterns of ice-rafted detritus in the glacial North Atlantic (40-55N). Paleoceanography, 8 2 , 175-192.

Heinrich, H. 1988. Origin and consequences of cyclic ice rafting in the northeast Atlantic Ocean during the past 130,000 years. Quat. Res., $29(2), 142-152$.

Hutter, K., H. Blatter and M. Funk. 1988. A model computation of moisture content in polythermal glaciers. 7. Geophys. Res., $93(\mathrm{~B} 10)$, $12,205-12,214$.

Lliboutry, L. 1976. Physical processes in temperate glaciers. J. Glaciol., 16 (74), 151-158.

Lliboutry, L. 1979. Local friction laws for glaciers: a critical review and new openings. 7. Glaciol., 23 (89), 67-95.

Lliboutry, L. 1981. A critical review of analytical approximate solutions for steady state velocities and temperatures in cold ice-sheets. Z. Gletscherkd. Glazialgeol., 15 (2), 1979, 135-148.
Lliboutry, L. 1987. Realistic, yet simple bottom boundary conditions for glaciers and ice sheets. J. Geophys. Res., 92 B9), 9101-9109.

MacAyeal, D. R. 1993a. Binge/purge oscillations of the Laurentide ice sheet as a cause of the North Atlantic's Heinrich events. Paleoceanography, 8 6), $775-784$.

MacAyeal, D. R. 1993b. A low-order model of the Heinrich event cycle. Paleoceanography, 8 (6), 767-773.

Nye, J. F. 1959. The motion of ice sheets and glaciers. 7. Glaciol., 3 26), 493-507.

Robin, G. de Q. 1955. Ice movement and temperature distribution in glaciers and ice sheets. J. Glaciol., 2 18), $523-532$.

Walder, J.S. and A.C. Fowler. 1994. Channelized subglacial drainage over a deformable bed. J. Glaciol., 40 134), 3-15.

Yuen, D. A. and G. Schubert. 1979. The role of shear heating in the dynamics of large ice masses. J. Glaciol., 24(90), 195-212.

MS received 7 November 1994 and accepted in revised form 28 March 1995 